\title{
El vídeo-ensayo en la formación audiovisual del profesorado
}

\section{O vídeo-ensaio na formação audiovisual dos professores}

The video-essay on audiovisual training of teachers

\author{
Angel García-Roldán \\ angarrol@gmail.com \\ Escuela Universitaria de Magisterio "Ia Inmaculada". \\ Departamento de Didáctica de la Expresión Musical, Plástica y Corporal.
}

Facultad de Bellas Artes de la Universidad de Granada.

Departamento de Escultura.

\section{RESUMEN}

El vídeo-ensayo como forma de pensamiento audiovisual tiene sus máximos referentes en el denominado cine de ensayo y algunas de sus producciones pueden ser incluidas dentro del ámbito del videoarte. Sus características pedagógicas lo convierten en una estrategia de indagación y aprendizaje audiovisual apropiada para la enseñanza artística, especialmente en la comprensión de las diferentes formas, procedimientos y técnicas relacionadas con el audiovisual contemporáneo. En este artículo se recoge una experiencia de vídeo-ensayo en el ámbito de la formación inicial del profesorado que sirve para ilustrar su carácter pedagógico y la amplitud de sus posibilidades en la enseñanza.

Palabras clave: Video-ensayo, Análisis Audiovisual, Metodologías artísticas de investigación, Cultura visual, $A / r /$ tografía.

\section{RESUMO}

O vídeo-ensaio como forma de pensamento audiovisual tem os seus maiores referentes no denominado cinema de ensaio e algumas das suas produções podem até ser incluídas no âmbito da videoarte. As suas características pedagógicas convertem-no numa estratégia de indagação e aprendizagem audiovisual apropriada para o ensino artístico, especialmente na compreensão das diferentes formas, procedimentos e técnicas relacionadas com o audiovisual contemporâneo. Neste artigo dá-se conta de uma experiência de vídeo-ensaio no âmbito da formação inicial de professores que serve apara ilustrar o seu carácter pedagógico e a amplitude das suas possibilidades no ensino.

Palavras-chave: Vídeo-ensaio, Análise audiovisual, Metodologias Artistícas de Investigação, Cultura Visual, $A / r /$ tografia 


\section{ABSTRACT}

The video-essay as a form of visual thinking has its points of reference in the experimental film and some of his productions can be included within the scope of video art. His pedagogical features make it a learning strategy of inquiry appropriate for visual arts education, especially in the understanding of different forms, procedures and techniques related to the contemporary audiovisual. This article contains a video-essay experience in the field of initial teacher training which serves to illustrate the pedagogical nature and extent of their ability in teaching.

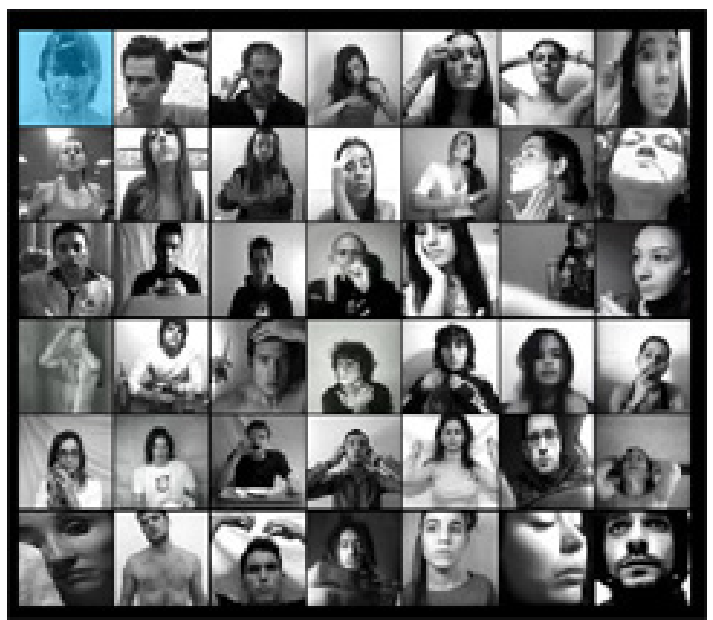




\section{EL VÍDEO-ENSAYO EN LA FORMACIÓN AUDIOVISUAL DEL PROFESORADO}

¿Puede una producción videográfica resultante de un proceso de aprendizaje convertirse en un ensayo audiovisual en su deseo por asimilar y debatir algunas cuestiones relacionadas con el arte y la educación?

Para contestar a esta cuestión es necesario que primeramente tratemos de definir qué es y qué supone un ensayo audiovisual y seguidamente planteemos algunas cuestiones relativas a su concreción en el aula.

Desde el punto de vista semántico un ensayo es una prueba, un intento y desde que el vocablo fue introducido por Michel de Montaigne significó: ejercicio, preludio, prueba, tentativa, tentación y el verbo 'ensayar': tantear, verificar, probar, experimentar, inducir a tentación, exponerse al peligro, correr un riesgo (Picazo, 2001, 25). A partir de entonces su significado se ha visto ampliado con la idea de ejercicio, esto es, de tentativa en un proceso de aprendizaje en el que el autor se muestra en cada momento de la experimentación y que se hace más evidente en el contexto audiovisual.

El vídeo-ensayo como otras expresiones ligadas a entorno audiovisual, mantiene una clara influencia de la tradición literaria. El ensayo literario como género es previo a cine de ensayo y el film-ensayo como producción reflexiva audiovisual es anterior al vídeo-ensayo que implica una adaptación singular de la tecnología del vídeo a las formas de plantear el discurso retórico de la imagen de orientación ensayística. No obstante, sí el ensayo permite: «elaborar una forma artística que conserva una poderosa vertiente filosófica permitiendo pensar ideas y exponerlas de forma personalizada y asistemática» (García Martínez, 2006, 75); el vídeo-ensayo puede plantearse como un discurso reflexivo realizado a partir de imágenes -fijas y en movimiento- y sonidos, cuya estructura responda a los intereses personales del propio autor que se plantearán y ajustarán de forma libre en el propio proceso de realización. Desde este planteamiento el vídeo-ensayo puede considerarse como una forma narrativa del pensamiento audiovisual desarrollado a partir de las herramientas retóricas que se concretan en el propio proceso y cuyo papel no es otro más que el de proporcionar el gesto necesario a la forma artística en la misma dirección que la planteada por Adorno respecto al ensayo literario. Al igual que éste, el vídeo-ensayo genera también una problemática sobre la relación que se establece entre sujeto y objeto. Al inicio de El ensayo como forma, publicado en Notas sobre la literatura (1974), Theodore Adorno manifiesta que el ensayo no es más que un producto ambiguo que carece de tradición formal, circunstancia que le permite la libertad de referirse a un objeto previamente formado y alejarse de planteamientos y construcciones narrativas definitivas. A partir de este enfoque se plantea la necesidad de concretar el gesto espontáneo del autor, lo que obligará a una interpretación activa por parte del lector -en nuestro caso espectador-. Es precisamente en esta relación donde se manifiesta su proximidad al arte en tanto que lo comunicado se constituye además como una reelaboración subjetiva del propio interprete.

Sin embargo, no podemos olvidar otra consideración importante, anteriormente aportada por Georg Lukács en el ensayo que abre El alma y las formas (1911), donde nos presenta el ensayo como una forma artística plena: «El ensayo habla siempre de algo ya formado o, en el mejor de los casos, de algo que ya ha existido en otra ocasión; es, pues, por su esencia por lo que no extrae cosas nuevas de una nada vacía, sino que meramente ordena de nuevo las que ya en algún momento estuvieron vivas» (Lukács, 1975, 28). Para Lukács el ensayo no es más que una forma directa de transmitir una experiencia que en sí misma recoge las cuestiones fundamentales respecto a la definición del propio género y sus propios límites formales y esenciales. La cuestión fundamental, en este caso, es la consideración del ensayo mismo como obra de arte, como género artístico. Lukács defiende que aunque la configuración del ensayo se encuentre alejada del campo de las ciencias y próximo al arte, no deja de ser una forma autónoma de ambas convirtiéndose en una forma que se concreta en su propia vivencia: «...el ensayista necesita la forma solo como vivencia, y solo la vida de la forma, la realidad anímica contenida en ella», más adelante aclarará: «Las vivencias para cuya expresión nacen los escritos del ensayista, no se hacen conscientes en la mayoría de los hombres más que en la contemplación de las imágenes o en la lectura de los poemas» (Lukács, 1975, 25-26). 
En todo caso, lo que si queda claro es que el cualquier tipo de ensayo plantea una indagación especulativa que se aleja de la rigidez de cualquier sistema filosófico y desarrolla una perspectiva desde donde fundamentar o sostener determinadas posiciones en relación a nosotros mismos, los demás y la amplitud simbólica de las imágenes que nos rodean. Es por esta razón que las imágenes que forman un vídeo-ensayo no dejan de ser más que una parte de una hermenéutica visual personal y compartida en la que se procesarán todo tipo de imágenes-experiencia, que darán como resultado un discurso audiovisual complejo e inacabado capaz, según Adorno, de relativizar su forma: «El ensayo tiene que estructurarse como si pudiera suspenderse en cualquier momento. Piensa discontinuamente, como la realidad es discontinua, y encuentra su unidad a través de las rupturas, no intentando taparlas» (Adorno, 2003, 26).

El vídeo-ensayo, por tanto, desarrolla un camino de búsqueda y exhibe su especulación en cada momento de su realización, evidenciando sus propias limitaciones y potencialidades a través de distintas herramientas que generan su discurso como la edición -o montaje- y la acción performática, y cuyo objetivo no es otro mas que el de desarrollar y enriquecer la propia expresividad y opinión del autor. Estas especificaciones cobrarán una especial importancia en el ámbito del aprendizaje audiovisual y la enseñanza artística permitiendo una diversidad de discursos y flujos de influencia entre todos ellos que lo convertirán en una forma creativa de investigación y aprendizaje audiovisual especialmente adecuada en la enseñanza artística -especialmente interesante en la formación del profesorado de educación primaria y secundaria-.

Hasta aquí una breve introducción de qué es un ensayo audiovisual pero nos queda por resolver la cuestión de qué supone esta estructura de pensamiento visual. Hace cincuenta y ocho años que Rudolf Arnheim publicó por primera vez El pensamiento visual (1954) y aun hoy sigue siendo el punto de partida de cualquier investigación basada en las imágenes o en las Artes. En esta obra Arnheim explicaba como las operaciones cognoscitivas llamadas pensamiento no son un privilegio exclusivo de los procesos intelectuales internos, sino que son también ingredientes esenciales de la propia percepción convirtiéndola en una "acción sensorial inteligente" que caracteriza de forma determinante al pensamiento visual. Nuestra capacidad para ver y conectar las distintas miradas resulta cada vez más rápida, influenciados por la formas de una cultura audiovisual contemporánea que nos hiperestimula orientando nuestro conocimiento a través de sus medios para visualizar con amplitud y perspectiva mediática la existencia humana. Esta es la razón por la que la comprensión de la realidad queda mediatizada y suscrita a un tipo de conocimiento que requiere de la imagen como complemento para hacerla más comprensible y evidente, ayudándonos a establecer un nuevo tipo de relaciones con nuestro entorno social inmediato.

Inicialmente el término audiovisual empezó a usarse en Estados Unidos en los años 30 con la aparición del cine sonoro aunque no será hasta la década de los 50 que sería empleado en el contexto audiovisual francés para hacer referencia a las distintas técnicas de difusión simultáneas. Desde entonces su concepto se verá ampliado y substantivado incidiendo en la integración entre lo auditivo y lo visual con el fin de producir nuevos lenguajes para manifestar nuevas realidades sensoriales a través de mecanismos como: la armonía, en la que cada sonido es correspondido por una imagen; la complementariedad, que enriquece los aportes de cada elemento; el refuerzo, que permite el enriquecimiento significativo de las partes; o el contraste, que plantea la creación de significados a través de la distancia y diferencia entre ambos.

El vídeo-ensayo como estrategia comunicativa y forma de pensamiento queda adscrito, como adelantábamos al inicio, al razonamiento audiovisual planteado por el Film-ensayo ${ }^{1}$ - un modo de producción audiovisual que ha proliferado en los últimos años dentro de las disciplinas del Cine y las Bellas Artes y cuyo origen se remonta a 1920 a partir de los límites tradicionales de las disciplinas del cine, como fusión híbrida entre las categorías de la ficción y el documental-.

\footnotetext{
1 Puede consultarse como complemento audiovisual la web creada con el fin de mostrar algunos ejemplos de la historia del Film-ensayo y ampliada con otros de cine-experimental.

En: http://www.wix.com/veraiconoproduccion/film-ensayo [Consultada 20 de enero de 2012]
} 
Como género no quedará articulado hasta la aparición del manifiesto de Hans Richter, El Ensayo de Cine: Una Nueva Forma de Cine Documental (1940), [Der Filmessay: Eine neue Formulario des Dokumentarfilms], en el que el autor teorizó sobre el nuevo formato o género filmográfico que facilitaba hacer visible lo "invisible", esto es; mostrar el complejo mundo de los pensamientos de un artista a través de la pantalla. A diferencia de la película documental, que presenta los hechos y la información, el cine de ensayo produce un pensamiento complejo formado por reflexiones que no están necesariamente ligadas a la realidad y que pueden ser contradictorias, irracionales o excepcionales. De esta manera en una película de ensayo, el autor afirma y transgrede las normas y parámetros de la práctica documental tradicional, concediendo a la imaginación toda su potencialidad artística para operar libremente.

No obstante el intento de delimitación de este género ha provocado su confusión con el documental performativo, las películas de montaje o la vanguardia fílmica y al igual que sucede en el campo literario se ha llegado a negar su categorización como género o estilo especifico (García Martínez, 2006, 85).

En oposición al género estrictamente documental, el Film-ensayo es considerado como ese espacio donde se puede presentar la verdad sin ambigüedades y una relación con la historia no arbitraria, donde también tiene cabida la contradicción y el juego. El replanteamiento del género del documental y la proliferación de ensayos audiovisuales producidos indistintamente por artistas y cineastas desde el último cuarto de siglo pasado hasta nuestros días, han impulsado el desarrollo de un nueva forma híbrida que en la práctica desdibuja las categorías del cine y del arte, flexibilizando tanto las prácticas de producción como las de exposición o exhibición. Hoy, más que nunca, los artistas muestran sus películas en festivales y salas de cine, y los cineastas exhiben sus obras en galerías y museos; es precisamente aquí donde el ensayo audiovisual se ha mezclado y confundido con la formas habituales del videoarte. Para algunos colectivos de videoartistas, como el español Colectivo Interferencias, la producción videográfica en la actualidad «...no se plantea como un simple medio para evocar un mensaje cualquiera, sino que se hace a sí mismo objeto -fin, en su caso-. El artista se transforma con la obra y, de esta misma manera, la obra pasa a ser expuesta para su recepción. Con una pretensión: devolverle al espectador la mirada sobre sí» (Le Mag, 2009, n으).

Las aportaciones de Richter resultarán cruciales para la aparición del ensayismo audiovisual en el contexto del arte, apoyado posteriormente por la aparición del vídeo como nueva tecnología que sustituiría a la película tradicional como soporte de las experimentaciones. Sus películas y escritos se convirtieron en referencias esenciales para un nutrido grupo de artistas y cineastas de la talla de Kenneth Anger, Maya Deren, Stan Brackhage, Michael Snow, Jonas Mekas, Jack Smith y Andy Warhol, cuyas filmografías fueron deudoras de sus influencias.

De otra parte, el ensayo audiovisual europeo se plantea como una derivación del género documental, prominentemente articulada por cineastas franceses, entre los que destacan autores clave como Alexandre Astruc y su seguidores más destacados; Jean-Luc Godard y Chris Marker. Sí Astruc introduce el concepto de cámera-stylo, planteando la posibilidad de convertir al cine en un medio de expresión como el resto de las artes: «un lenguaje -el cine- mediante el cual el artista puede expresar su pensamiento, por muy abstracto que sea, o traducir sus obsesiones exactamente igual que ocurre con el ensayo o con la novela» (Astruc, 1948); Jean-Luc Godard y Chris Marker -entre otros- Ilevarán a la práctica sus proposiciones en relación a un cine de ensayo. Casi a la par otros cineastas alemanes como Rainer Werner Fassbinder, Werner Herzog, Hans Syberberg, Sanders Helke, Alexander Kluge, Wim Wenders, Hartmut Bitomsky y Harun Farocki, plantearán propuestas de ensayo fílmico intercalándolas entre sus producciones habituales.

En el vídeo-ensayo se enfatiza más el proceso que el resultado ya que es en su tratamiento donde se produce el proceso de reflexión. Las ideas que se disponen a través de las imágenes no pueden ser consideradas como previas a la propia acción o intervención audiovisual ensayística y sólo es considerado como punto de partida el deseo del autor a indagar en el discurso audiovisual. El vídeo-ensayo puede ser vista además como una estrategia didáctica que favorece el de- 
sarrollo de un pensamiento crítico audiovisual y que nos permite entender su construcción narrativa desde la experiencia propia. Por todo ello, podemos contemplar el vídeo-ensayo como una forma o artificio que ensambla tanto el pensamiento como el medio, eliminando la distancia entre la representación y la reflexión. De esta manera, además, superamos el aspecto ilustrativo que tradicionalmente se le ha otorgado a la imagen -ya sea fija o en movimiento- y fomentamos una lectura autónoma de las imágenes respecto al texto escrito o hablado. No obstante, el video-ensayo es también susceptible a la incorporación de palabras y todo tipo de textos escritos o narrados.

Son estas consideraciones la que nos hacen plantearnos su posible valor pedagógico en la enseñanza artística y su utilidad como estrategia educativa que debemos poner en práctica en el aula. Desde esta perspectiva el vídeo-ensayo se muestra como un discurso audiovisual a través de una quedado demostrado por algunos autores que son referencia obligada la Educación Artística (Gardner, 1994). Esta retroalimentación en los distintos discursos no necesariamente habrá de desarrollarse en el momento, pero justificará la necesidad de generar un conocimiento -contrastándolo y exponiéndolo a un juicio externo- para evitar perderse en el tiempo y favorecer la generación de respuestas, reflexiones paralelas, citaciones y autorreferencias de los propio autores a la obra. Es esta característica la que nos permitió plantear una propuesta didáctica inscrita en el contexto de la formación inicial del profesorado ${ }^{2}$ basada en el vídeo-ensayo a partir de un enfoque $a / r /$ tográfico que hiciera posible desarrollar distintas formas ensayísticas audiovisuales como forma de aprendizaje -previa a la realización de otras propuestas ligadas al ámbito del videoarte- y que además favoreciera la experimentación de distintos conceptos y procesos inherentes al lenguaje audiovisual. Este planteamiento ayudó a alcanzar además ambos objetivos e hizo posible conformar una obra audiovisual colectiva a través de las diferentes visiones o miradas construidas a partir del leitmotiv del proyecto, resumido en el título-propuesta: Prólogo para un humano perfecto ${ }^{3}$.

Detalle de la Web del proyecto: Prologo de un humano perfecto. 2010.

La imagen hace referencia al Video-ensavo: Proloque to a crvbabv Perfect, del alumno: Mario Romero.

forma artística que concreta el pensamiento y la acción, permitiéndonos: por un lado, desarrollar una serie de ideas y conceptos a través de la creación audiovisual en el que cada autor experimenta y explora con su propio formato, y de otra parte, experimentar la necesidad de comunicar y establecer estos enunciados a través de un ciclo comunicativo, en tanto que la obra pueda influir sobre otras, generando y enriqueciendo el debate o simplemente poniendo a disposición los conocimientos desarrollados. La propia acción creadora tiene un valor didáctico en sí misma, tal y como ha
2 El alumnado pertenecía al primer curso de Grado de Maestro de Educación Primaria y en concreto a la asignatura de carácter obligatorio, Enseñanza y Aprendizaje de las Artes Visuales y Plásticas (curso 2010-11), que es impartida por el Departamento de Didáctica de Expresión Musical, plástica y Corporal en la Facultad de Ciencias de la Educación de la Universidad de Granada.

${ }^{3}$ La propuesta, Prólogo para un humano perfecto, supone la realización de un vídeo-ensayo de corta duración sobre la pregunta: ¿cómo es un humano perfecto? Para su realización se destinaron aproximadamente dos semanas de trabajo y fue desarrollada fuera del horario habitual de la asignatura. 
Antes de describir la propuesta y mostrar algunos de sus resultados es necesario realizar algunas consideraciones que deberán tenerse en cuenta para analizar la amplitud y profundidad del proyecto:

1. El proyecto Prólogo para un humano perfecto no es sólo una experiencia realizada en el aula sobre el medio audiovisual, es en sí un proyecto especulativo de reflexiones entrecortadas - una pieza colectiva en el que se muestran todas las experiencias performativas- sobre la reveladora idea de descubrir en "lo humano" un espacio para su reflexión.

2. En Prólogo para un humano perfecto lo fragmentario no es un fin en sí mismo, sino un punto de partida que define la estética global del conjunto y de cada una de las partes audiovisuales, en beneficio de la creatividad y la comunicación entre sus creadores. Es la consecuencia directa de una lógica que mantiene abiertas las posibilidades de diálogo entre los productores del macro-ensayo y los espectadores potenciales. Por eso, mostramos todo el énfasis en lo parcial frente a la totalidad, que será descrita en una segunda fase de realización con la intención de cerrar los flujos e intercambios generados durante la realización del proyecto. De esta manera los vídeo-ensayos, al mismo tiempo que se van realizando, son alojados en un servidor-web que permite una actualización constante de los contenidos, su consulta permanente y el flujo retroalimentativo entre ellos ${ }^{4}$.

3. El ensayo que supone cada una de las videografías realizadas por los estudiantes participantes en el proyecto y su conjunto, es precisamente eso: un prólogo, una idea previa, una tentativa o prueba donde ensayar las diferentes respuestas a la cuestión anunciada. Las respuestas no pueden ser otras que las acciones que reivindican la ambigüedad y oscilación del yo, evitando de esta manera caer en un dogmatismo de imágenes y de perspectivas, aunque no por ello dejen de ocurrir circunstancias de referencialidad y cita, o ciertos rasgos miméticos en las experimentaciones generadas.

\footnotetext{
4 Consultar web del proyecto en: http://www.wix.com/veraiconoproduccion/prologoparaunhumanoperfecto [Consultada 20 de enero de 2012]
}

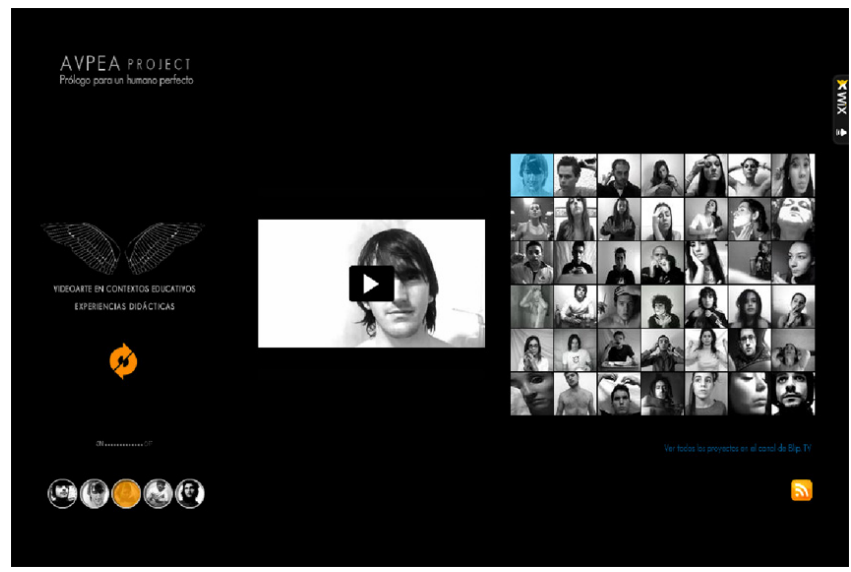

Detalle de la Web del proyecto: Prologo de un humano perfecto. 2010. La imágenes muestran el conjunto de videoensayos realizados por los estudiantes y la apariencia de la web.

4. Las tres obras proyectadas The Perfect Human (1967) Jørgen Leth; The Five Obstruction (1995) Lars von Trier \& Jørgen Leth; y mi propio trabajo Prologue to a perfect human (2010) cumplen la función de preámbulo e introducción del proyecto, incluyen alusiones y citaciones constantes entre sí que inducen a los participantes a similares procedimientos y estrategias de referencialidad-justificando y conectando, a la vez, cada uno de los distintos procesos llevados a acabo- a través de los planteamientos y premisas del proyecto ${ }^{5}$. El meta-discurso desarrollado a partir del propio título del proyecto plantea el punto de partida que proporcionará un conjunto de conclusiones visuales a modo de preguntas abiertas; relaciones que establecen y originan el discurso, concretando el aspecto pedagógico y didáctico del proyecto, además de ser la causa orientadora de todas las acciones y sus posibles argumentaciones. En este sentido ha de destacarse la necesidad de establecer distintas formas de referencialidad como perspectiva de indagación, sugerida desde el trabajo del propio docente -que es a la vez artista e investigador-. A menudo consideramos que el arte contemporáneo permanece alejado de la escuela, pero qué ocurre si sus actores se intrucen en las aulas. En nuestra opinión

\footnotetext{
5 Las experiencias se plantean a través de las siguientes premisas: 1. La videografía final se editará en blanco y negro. 2 . El contexto de grabación será un fondo neutro, banco o negro a ser posible. 3. Las tomas realizadas sólo mostrarán primeros planos y se procurará que el sujeto no salga del encuadre. 4. El performer será el propio autor de la videografía. 5. Las acciones que se realicen han de ser cotidianas y repetitivas
} 
el docente-artista puede y debe mostrar sus indagaciones y reflexiones visuales en el aula, como una parte más de las experiencias siempre que queden justificadas pedagógicamente. El trabajo del docente-artista, en este sentido, no se presenta como un hito sino como un proceso de búsqueda similar al que los estudiantes van a desarrollar.

5. El Yo que constantemente es presentado en estos vídeo-ensayos no consiste en una cuestión enunciativa de lo que somos sino más bien la demostración circunstancial de la conciencia de cada uno de nosotros en el todo de una tarea colectiva. De alguna manera, la conocida frase de Michel de Montaigne, permite entender esta circunstancia: «Yo mismo soy la materia de mi libro». Esta es la idea que recogen todas estas auto-presentaciones con las que cada autor se coloca a sí mismo como ejemplo real y práctico de los problemas sobre los que reflexiona. De esta manera, cada uno de ellos se atreve a mostrarse para trazar la linea discontinua de su humano perfecto. Ensayarse a sí mismo, en el sentido de experimentarse o ejercitarse, es la intención desde la que se revela la necesidad del autorretrato con la que el ensayo y, en nuestro caso, el vídeo-ensayo muestra una gran correspondencia -tanto en el retrato como en el ensayo el autor se desvela y se reconoce adoptando diferentes grados de exposición, o lo que es lo mismo; de autobiografismo asumido con completa libertad-.

6. Es también importante destacar ese aspecto "inacabado" de la totalidad de los proyectos, que nos acerca aun más a la idea planteada por Adorno de un ensayo estructurado como sí fuese a suspenderse en cualquier momento. Indiscutiblemente este carácter provocador de "lo inacabado" es siempre una invitación al receptor para que asuma su protagonismo y lo concluya. En cierta forma, la advertencia: «Hoy he experimentado algo que espero entender en pocos días» con la que George Leth estructuraba su discurso en The human perfect (1967), plantea la misma necesidad de que el otro lo acabe o lo concluya; porque la experimentación audiovisual y su ensayo, como forma de pensamiento, implica el espacio y la espera que la harán más comprensible. Distancia en la cual, el interlocutor recuperará su protagonismo privilegiado.

\section{CONCLUSIONES}

El ensayo audiovisual es una travesía hacia la verdad repleta de paradas y digresiones, de incertidumbres e hipótesis, donde se manifiesta la noción de "obra abierta" confirmada como una realidad inacabada en la que indagación no plantea una conclusión definitiva y sólo puede ser abarcada desde la exposición de las ideas, que podrán ser completadas, corregidas o incluso validadas pero nunca completamente resueltas.

En este sentido el vídeo-ensayo supondrá un viaje cuyo mayor mérito reside en el esfuerzo del propio trayecto recorrido y cuya naturaleza subjetiva lo convertirán en un género que predispone al autor-creador y a su espectador a un incesante diálogo con el mundo que los rodea. En esta dirección supone también la identificación del pensamiento audiovisual en el momento de generarse, con la única certeza de mostrar las imágenes del proceso a un receptor-espectador que las habrá de concluir.

Constatamos, además, que durante las experiencias el alumnado realiza distintos juegos exploratorios personales, en las que las tentativas y conjeturas enriquecen su aprendizaje audiovisual y su autoconocimiento personal a través de su trabajo, permitiendo valorar los distintos aspectos narrativos de las imágenes y las posibilidades de ejercer sobre ellas una mirada reflexiva y crítica, que será comprendida como un modelo de actuación en el futuro, especialmente útil en los ámbitos de formación del profesorado. Por lo tanto, el tratamiento del vídeo-ensayo en la educación artística, sea cual sea su ámbito de aplicación, genera situaciones altamente motivadoras que lo convierten en una magnifico procedimiento para el aprendizaje audiovisual y una propuesta de indagación idónea y versátil de cara a cualquier área del currículum escolar, favoreciendo la transversalidad, la adquisición de competencias y una educación en valores. Sin duda, la distintas formas del ensayo audiovisual pueden asumirse como una experiencia didáctica que favorece el libre pensamiento del individuo receptor y emisor de todo tipo de mensajes visuales y audiovisuales, estableciendo nuevas formas de relación entre el arte contemporáneo y la enseñanza artística y creando vínculos significativos entre 
la experiencia de los estudiantes y las distintas formas de mensajes audiovisuales de su entorno.

En resumen, a través del vídeo-ensayo desarrollamos la capacidad de inferir significados y contextualizar los mensajes, sin necesidad de conocer al detalle el lenguaje audiovisual, haciendo uso de los medios audiovisuales como vehículo para expresar nuestra interioridad y disfrutar a nivel estético al mismo tiempo que transformamos nuestra la realidad.

\section{PRÓLOGO PARA UN HUMANO PERFECTO.}

Recursos y contenidos web desarrollados.

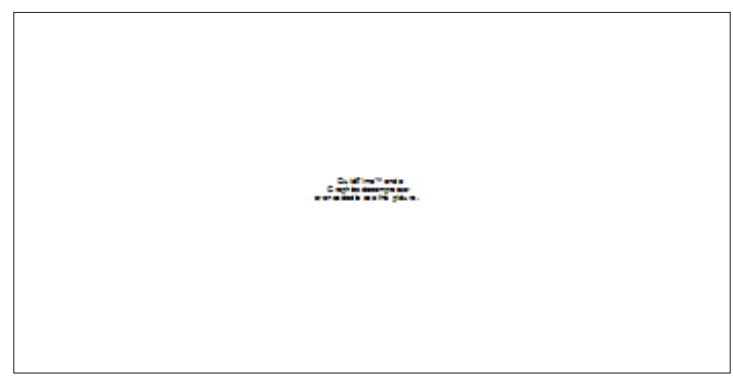

\section{CANAL DE VIDEOENSAYOS DEL PROYECTO}

En ellos se recogen las aportaciones de los estudiantes que se insertan con la la interfaz del canal en el blog de la asignatura. De forma automática son actualizados con cada aportación y permiten el visionado en linea de toda la producción del proyecto.

Recurso web utilizado: BLIP.TV.

En: http://blip.tv/

http://blip.tv/prlogo-de-un-humano-perfecto

[Consultada 20 de Diciembre de 2011]

PROLLGO PARA UN HUMANO PERFECTO

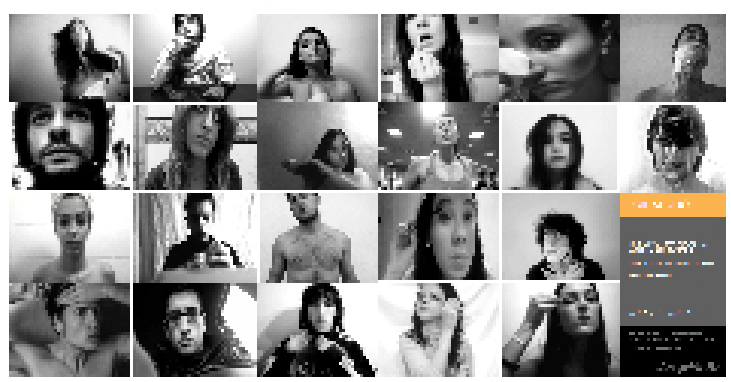

\section{PORTAFOLIO DIGITAL DEL PROYECTO}

Dossier-catálogo que incluye secuencias de still de cada proyecto describiendo como si se tratara de una linea de tiempo el desarrollo de cada videografía para su posterior análisis.

Recurso web utilizado: ISSUS

En: http://issuu.com/

http://issuu.com/angelgarciaroldan/docs/prologo_para_un_humano_perfecto_4_red_2/1\#share

[Consultada 20 de Diciembre de 2011]

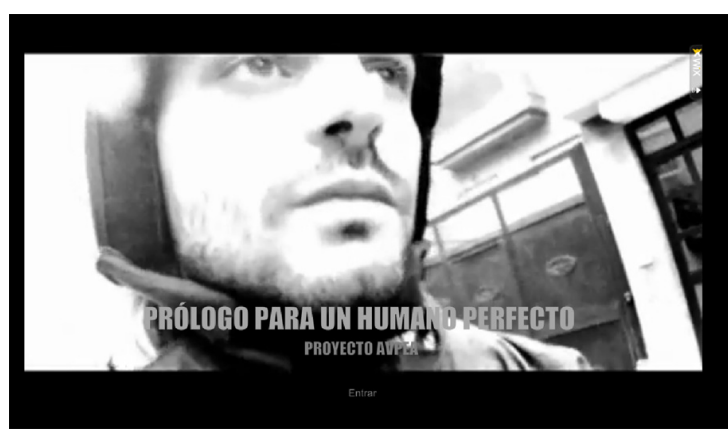

\section{WEB DEL PROYECTO}

Web del proyecto a través de la cual podemos tener acceso a todos los contenidos desarrollados.

Recurso web utilizado: WIX

En: http://es.wix.com/

http://www.wix.com/veraiconoproduccion/prologoparaunhumanoperfecto 


\section{REFERENCIAS BIBLIOGRÁFICAS}

ADORNO, Th. W. (2003)[1974]: "El ensayo como forma". En Notas sobre literatura, Vol.11. Madrid: Akal.

ARENAS, Ma E. (1997): Hacia una teoría general del ensayo. Construcción del texto ensayístico. Cuenca: Ediciones de la Universidad de Castilla-La Mancha.

ARNHEIM, R. (1998) [1954]: El pensamiento visual. Barcelona: Paidós.

ASTRUC, A. (1988) [1948]: Nacimiento de una nueva vanguardia: La caméra stylo. Madrid: Cátedra. [Originalmente publicado en L'Écran Français № 144].

BAZÍN, A. (2004)[1958]: ¿Qué es el cine?. Madrid: Rialp.

BERGALA, A. (2000): Qu'est-ce qu'un film-essai, en Le film-essai: identification d'un genre. Paris: Bibliothèque Centre Pompidou.

CATALÀ DOMÈNECH, J. Mạ (1999): El film-ensayo: la didáctica como una actividad subversiva. Archivos de la Filmoteca, Revista de estudios históricos sobre la imagen. $n$ ㅇ 34. Valencia. IVAC. 79-97.

CERVERA, V.; Hernández, B. y Adsuar Ma D. (eds.) (2005): El ensayo como género literario. Murcia: Universidad de Murcia.

GARDNER, H. (1994): Educación artística y desarrollo humano. Barcelona: Paidós.

GARCÍA MARTíNEZ, A. N. (2006): La imagen que piensa. Hacia una definición del ensayo audiovisual. Comunicación y Sociedad. Vol. XIX. No 2. 75-105.

http://dspace.unav.es/dspace/bitstream/10171/8332/1/20090618142319.pdf

[11, septiembre de 2011]

GARCÍA ROLDÁN, A. (2010): Film Ensayo y Experimental. En: Videoarte en Contextos Educativos. Tesis

http://www.wix.com/veraiconoproduccion/film-ensayo

[2, septiembre de 2011]

- (2010): Proyecto PHP. En Videoarte en Contextos Educativos. Tesis

http://www.wix.com/veraiconoproduccion/prologoparaunhumanoperfecto

[2, septiembre de 2011]

GÓMEZ TARÍN, Fco. J. (2011): El análisis de textos audiovisuales. Santander: Shangrila

http://www.shangrilaediciones.com/Materiales3-El-Analisis-Textos-Audiovisuales.pdf

[2, septiembre de 2011]

JARAUTA, Fco. (ed.) (1991): La transformación de la conciencia. Murcia: Universidad de Murcia.

JENKS, C. (ed.) (1995): Visual Culture, Londres y Nueva York: Routledge.

LIANDRAT-GUIGUES, S. y Leutrat, J. L. (2003): Cómo pensar el cine. Madrid: Cátedra.

LUKÁCS, G. (1975): El alma y las formas. Teoría de la novela. Barcelona: Grijalbo.

MAESO RUBIO, Fco. (2003): Todo el mundo es un artista: creatividad, imaginación, percepción visual y otras conductas artísticas. En R. Marín Viadel. (coord.): Didáctica de la educación artística para primaria. (Págs. 107-142) Madrid: Pearson Educación.
MAESO RUBIO, Fco.; Marfil Carmona, R. (2011): Artes Visuales y Educación Mediática. Posibilidades para una didáctica común. Congreso Internacional de Educación Mediática \& Competencia Digital. "La cultura de la participación”. Comunicaciones. Del 13 al 15 de Octubre de 2011. Segovia: Escuela de Magisterio. Universidad de Valladolid.

http://www.educacionmediatica.es/comunicaciones/Eje\%204/Francisco\%20Maeso\%20Rubio\%20-\%20Rafael\%20Marfil\%20Carmona.pdf

[20, noviembre de 2011]

MARÍN VIADEL, R. (coord.) (2003): Didáctica de la Educación Artística para Primaria. Madrid: Pearson Educación.

- (2005): Investigación en Educación Artística: temas, métodos y técnicas de indagación sobre el aprendizaje y la enseñanza de las artes y culturas visuales. Granada. Universidad de Granada.

- (2005): La 'investigación educativa basada en las artes visuales' o 'Arteinvestigación educativa'. En R. Marín Viadel (coord.) Investigación en educación artística: temas, métodos y técnicas de indagación sobre el aprendizaje y la enseñanza de las artes y culturas visuales. (Págs. 223-274). Granada: Universidad de Granada.

MIRZOEFF, N. (2003): Una introducción a la Cultura Visual. Barcelona: Paidós.

PICAZO, Ma D. (2001): "Introducción”, En M. De Montaigne. Ensayos I, Madrid: Cátedra.

ROLDÁN RAMÍREZ, J. (2003): Emociones reconocidas: formación, desarrollo y educación de las experiencias estéticas. En R. Marín Viadel (coord.): Didáctica de la educación artística para primaria. (Págs. 143-181). Madrid: Pearson Educación. 2003.

ROLDÁN RAMÍREZ, J. y Genet, R. (2012): Fotodiálogos: Preguntas y respuestas visuales para el aprendizaje de la fotografía. En J. Roldán, y R. Marín Viadel (2012): Metodologías Artísticas de Investigación (Págs. 162-195). Archidona: Algibe.

ROLDÁN RAMíREZ, J. y Hernández González, M. (2010): El otro lado. Fotografía y pensamiento visual en las culturas universitarias. Granada y Aguascalientes (México.): Universidad de Granada y Universidad Autónoma de Aguascalientes.

ROLDÁN RAMÍREZ, J. y Marín Viadel, R. (2012): Metodologías Artísticas de Investigación. Archidona: Algibe.

VV.AA. (2009): 21 LE MAG. no2. Colectivo Interferencias. 